\title{
Practical Synthesis of an L-Fructose-Derived Ketone Catalyst for Asymmetric Epoxidation of Olefins
}

\author{
Mei-Xin Zhao and Yian Shi* \\ Department of Chemistry \\ Colorado State University \\ Fort Collins, CO 80523 \\ Tel: (970)-491-7424 \\ Fax: (970)-491-1801 \\ Email: yian@lamar.colostate.edu
}

Supporting Information

\section{Table of Contents}

Spectral data of mesylate 3

S-2

Spectral data of alcohol 7

S-4

Spectral data of ketone ent-1

S-7 


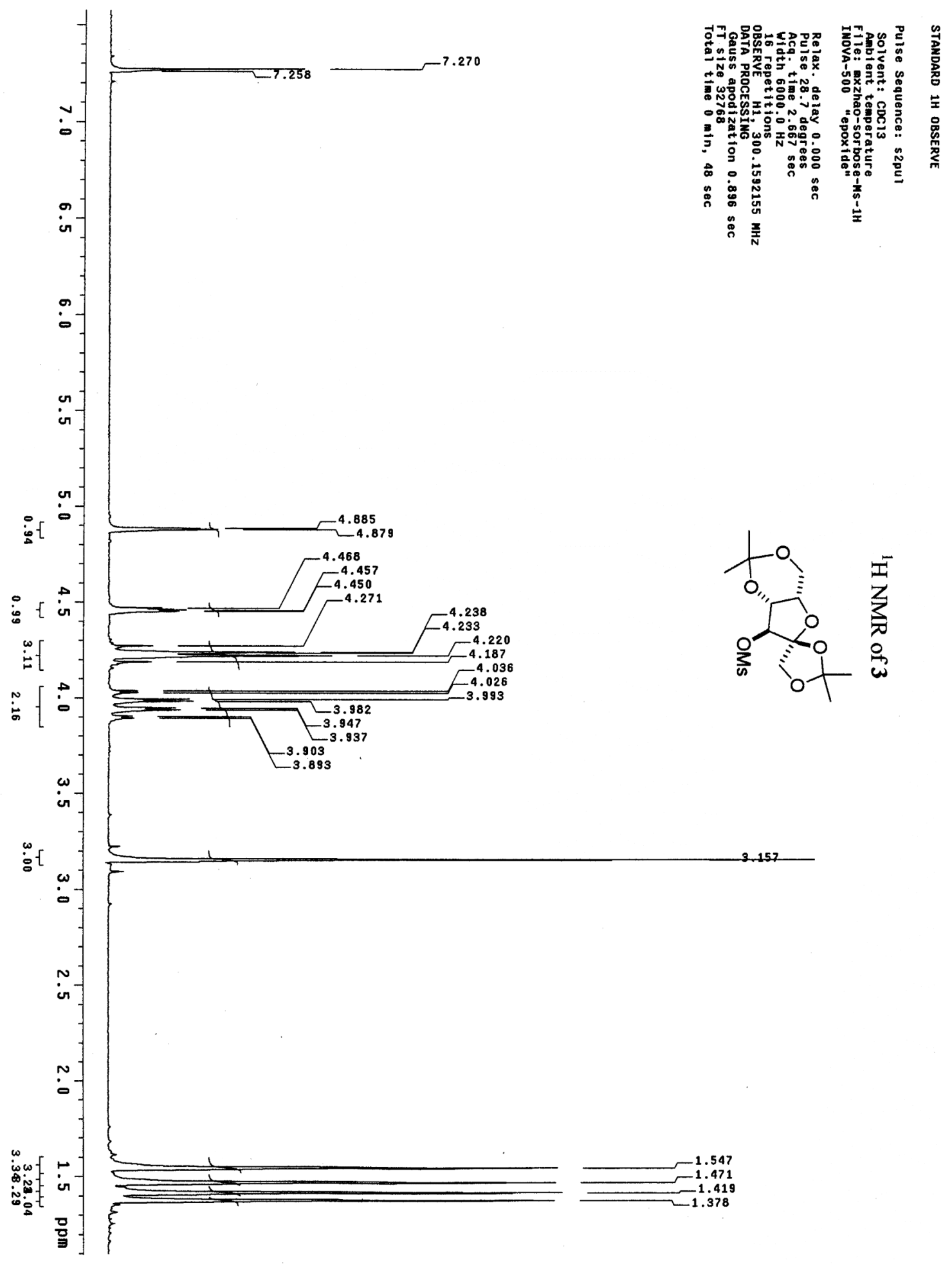




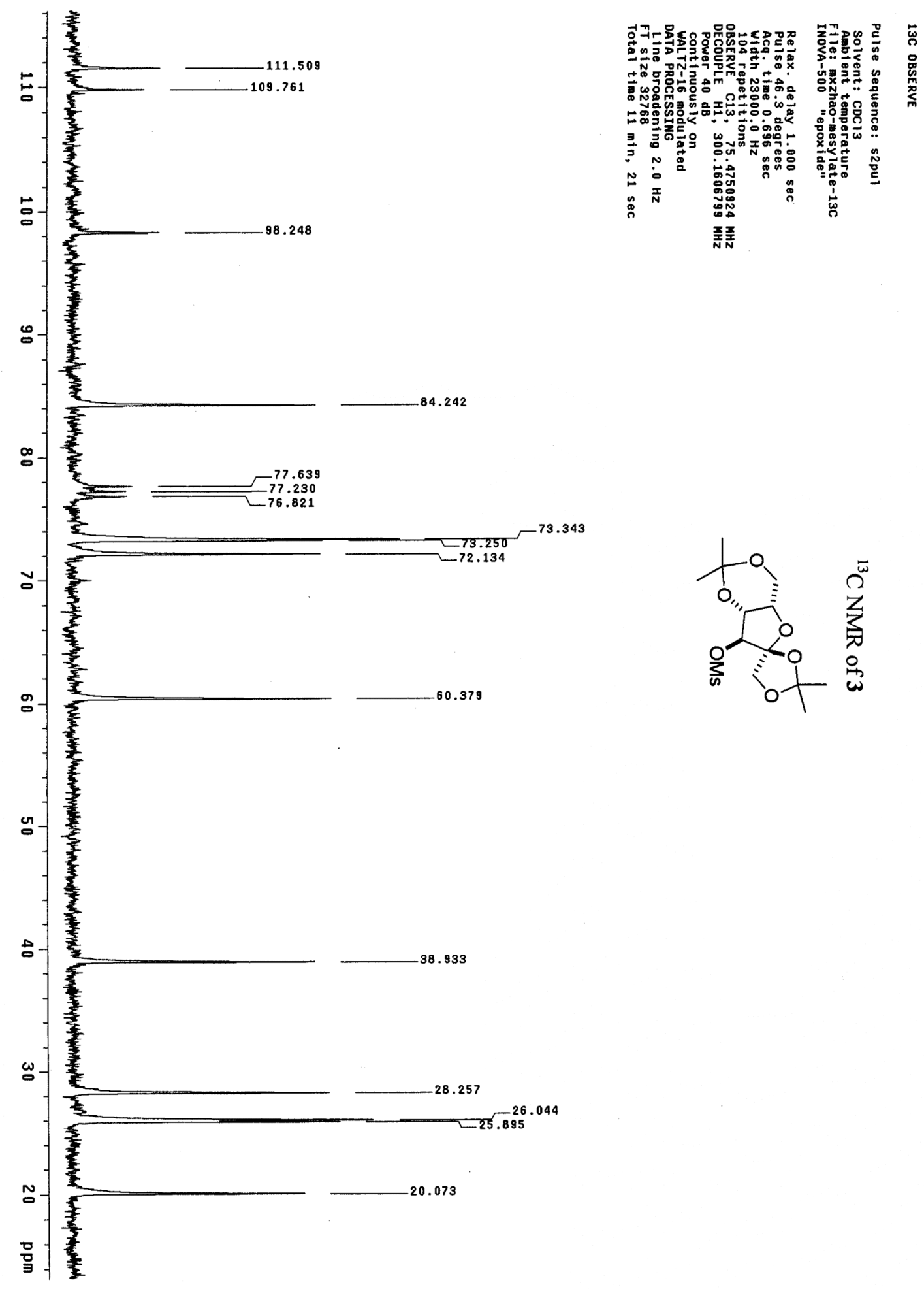




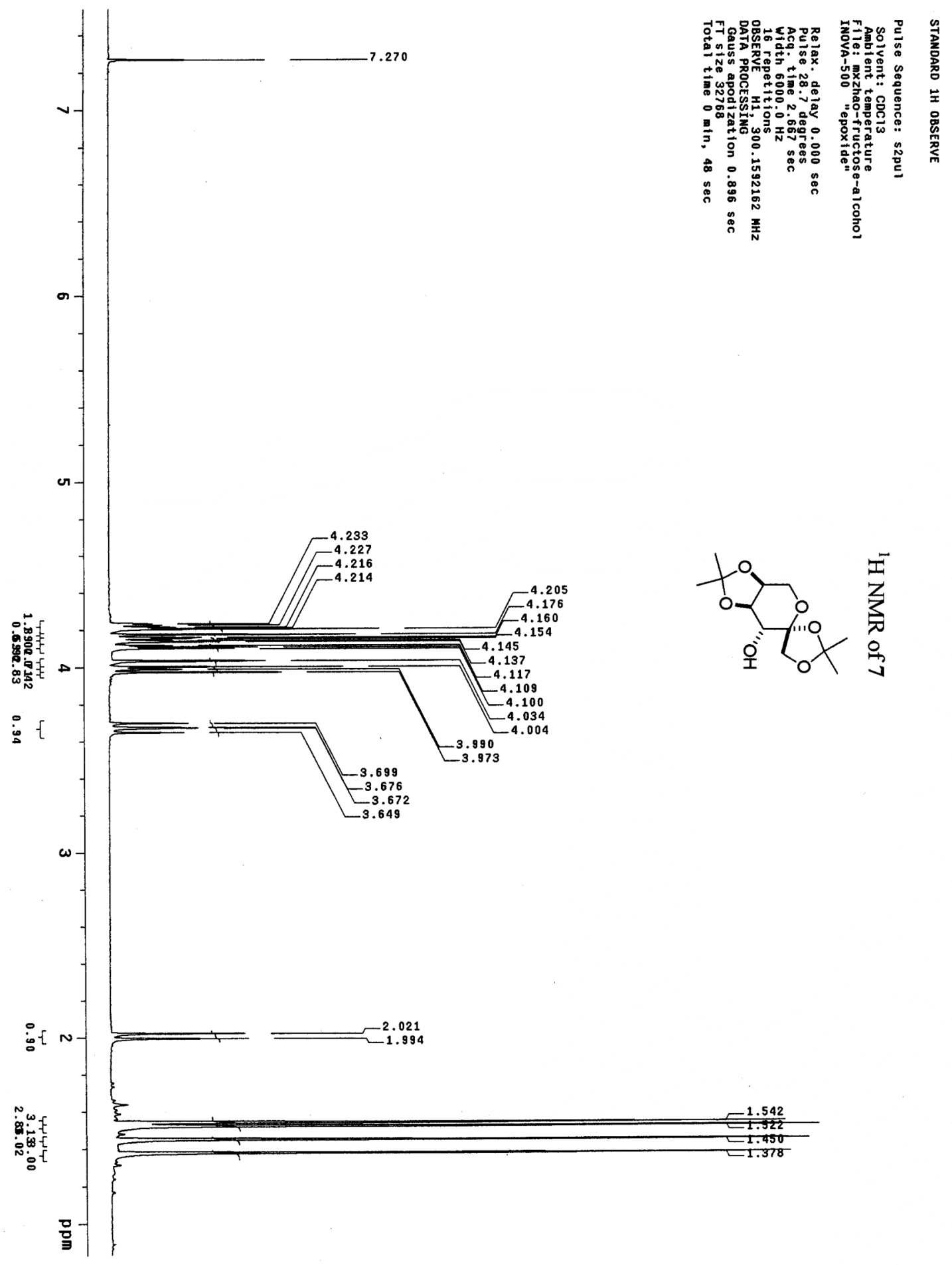



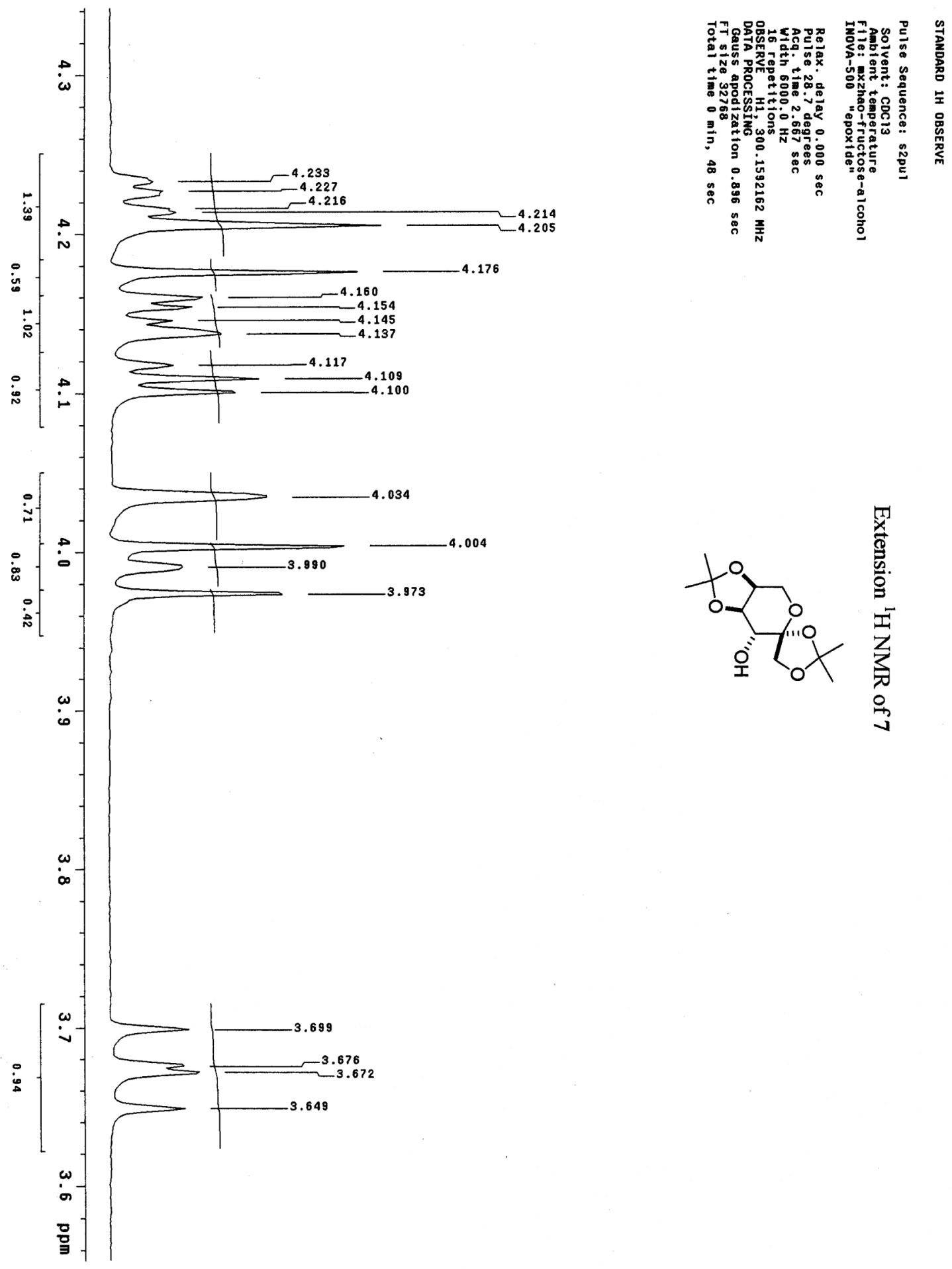

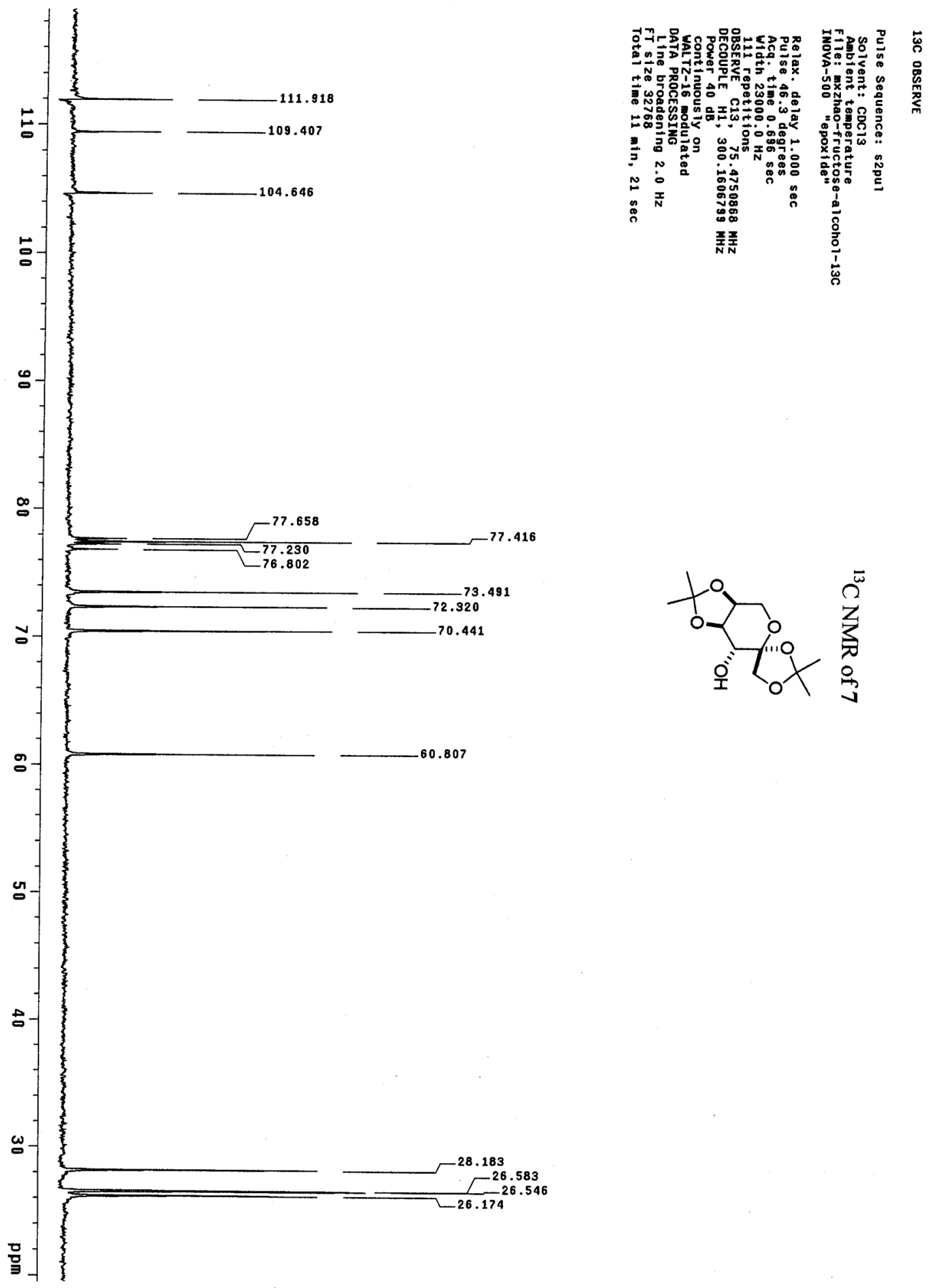


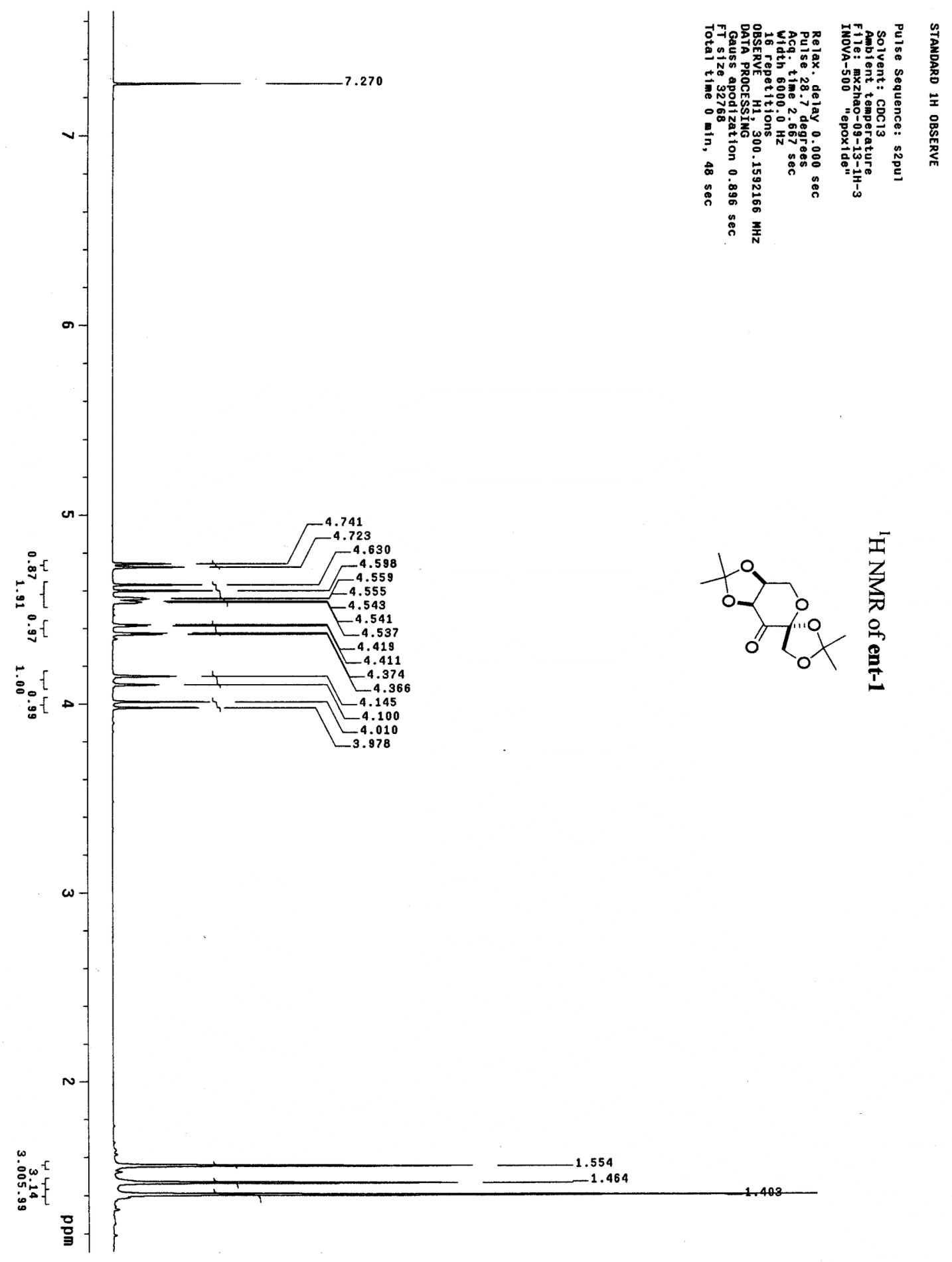




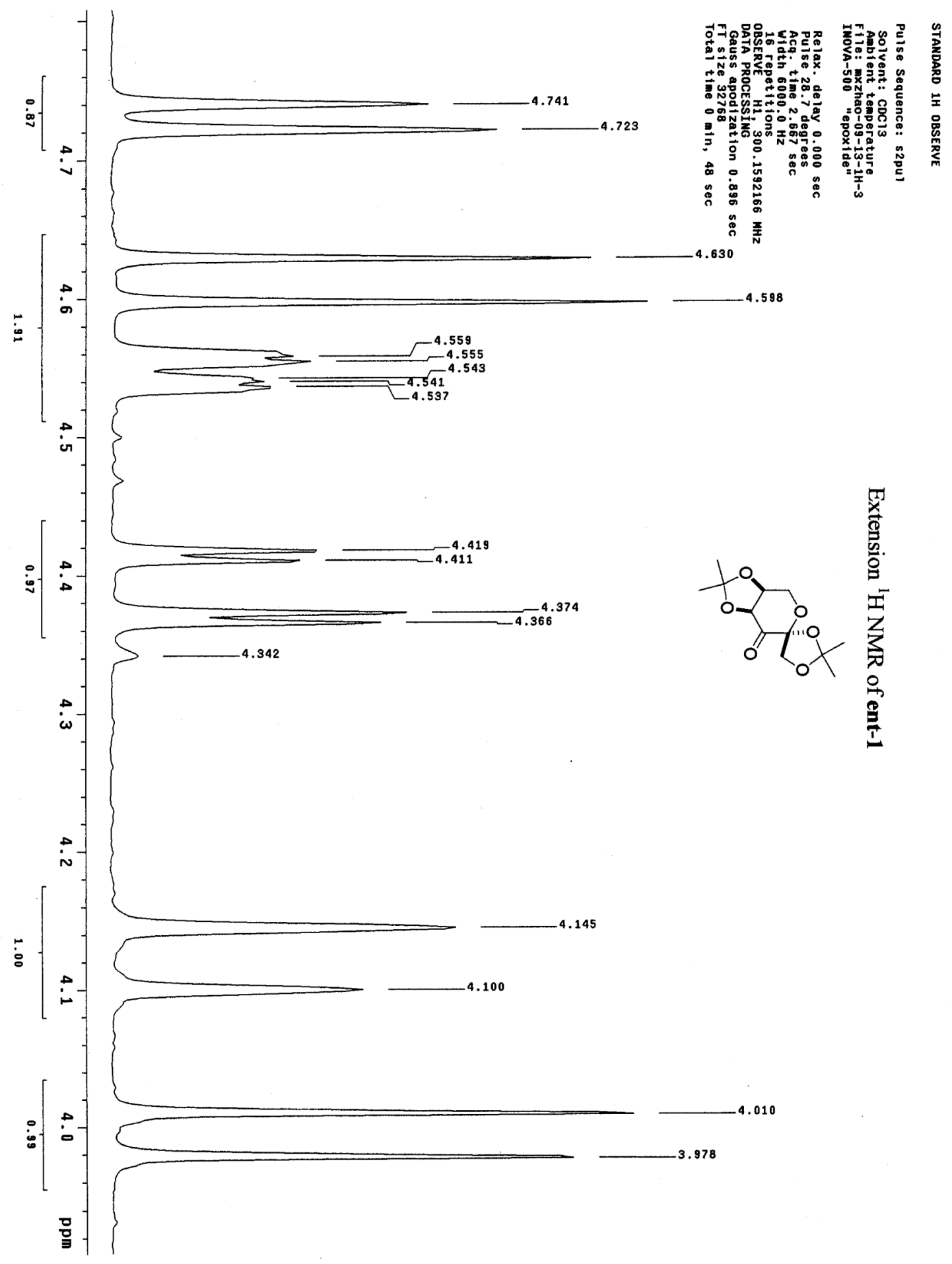




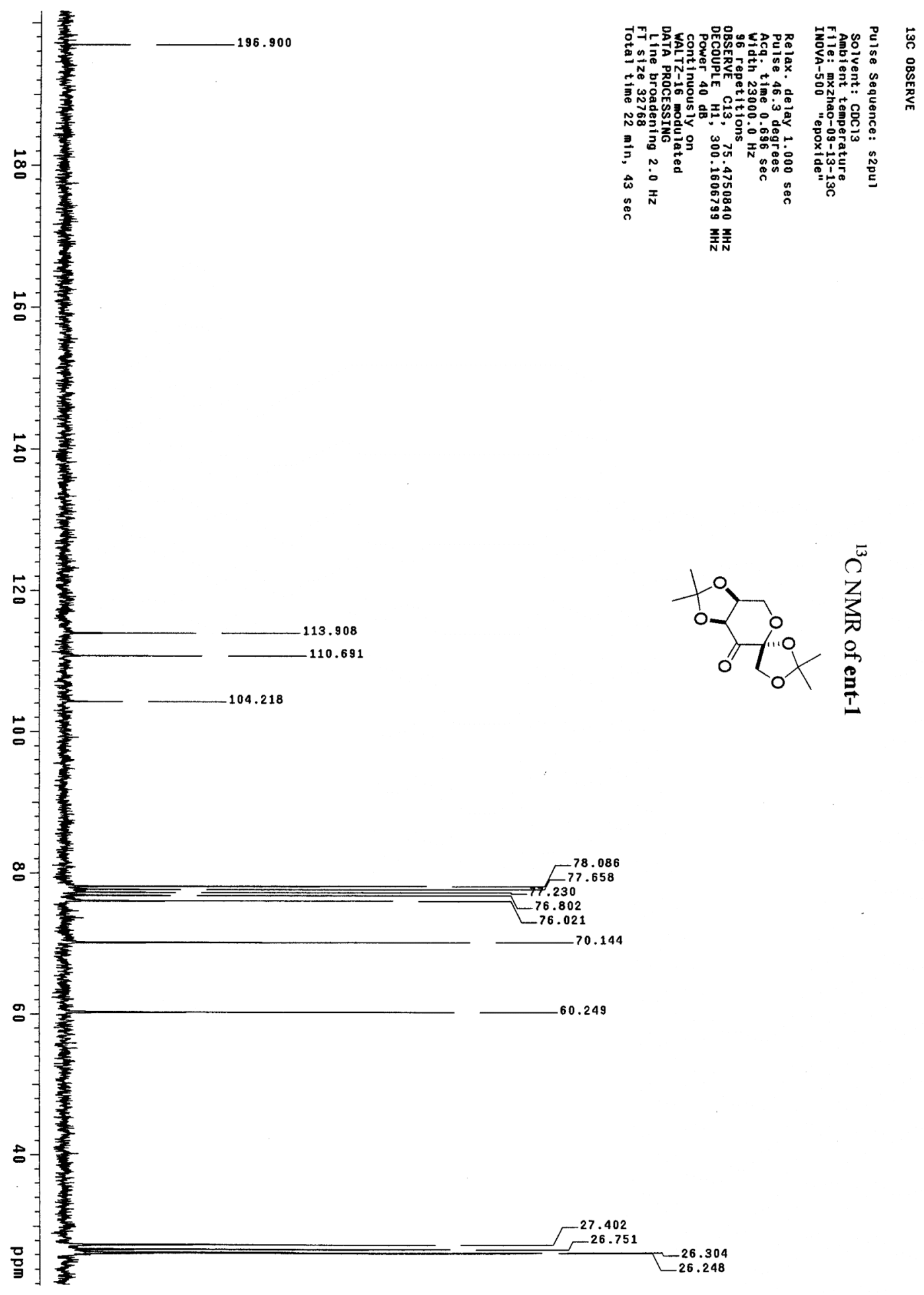

